\title{
Differential expression of acetyl-CoA carboxylase (accase) gene in chlorella ellipsoidea under nitrogen replete and deplete condition along with growth, lipid and fatty acid profile
}

\begin{abstract}
The present study aims at exploring the role of nitrogen on growth, lipid and fatty acid content and profile and corresponding differential Acetyl-CoA carboxylase (ACCase) gene expression in Chlorella ellipsoidea in BBM media. Chlorella ellipsoidea is a single-celled oleaginous microalgae and also a nutritious food with high protein content. C. ellipsoidea is a high quality biomass for producing algal oil. The growth of $C$. ellipsoidea was affected by $\mathrm{N}^{+}$condition (maximum OD: 0.1929; maximum cell density: $6820 \times 10^{5}$ ) and $\mathrm{N}^{-}$condition (maximum OD: 0.1284; maximum cell density: $1733 \times 10^{5}$ ). The lipid productivity of $C$. ellipsoidea under nitrogen repletion $\left(\mathrm{N}^{+}\right)$condition was $12 \%$ on dry weight basis while under nitrogen deplete condition $\left(\mathrm{N}^{-}\right)$it was $17 \%$ on $23^{\text {rd }}$ day of harvesting. C16 and $\mathrm{C} 18$ fatty acids comprised major components in both $\mathrm{N}^{+}$and $\mathrm{N}^{-}$conditions. The main components were palmitic acid (C16:0), oleic acid (C18:1), stearic acid (C18:0) and linoleic acid (C18:2) in cultures grown under $\mathrm{N}^{+}$condition and in $\mathrm{N}$-condition the main components were palmitic acid (C16:0), oleic acid (C18:1) and linoleic acid (C18:2). However, stearic acid (C18:0) showed a sharp decline in case of cultures grown under $\mathrm{N}^{-}$condition as compared to $\mathrm{N}^{+}$condition. Moreover, $\alpha$-linolenic acid (18:3) showed a sharp increase from $20.3 \%$ to $32.6 \%$ in $\mathrm{N}^{+}$to $\mathrm{N}^{-}$cultures. Quantitative real time PCR (qRT-PCR) analysis of ACCase gene from nitrogen repletion $\left(\mathrm{N}^{+}\right)$and nitrogen depletion $\left(\mathrm{N}^{-}\right)$conditions showed 0.6322 fold up regulation of ACCase gene in $\mathrm{N}^{-}$cultures of $C$. ellipsoidea cultures as compared to $\mathrm{N}^{+}$cultures. The growth rate was more in nitrogen repletion condition as compared to nitrogen depletion. However, the lipid percentage was more in Nitrogen depletion condition than in repletion condition. Fatty acid methyl esters (FAME) analysis showed that the main components were $\mathrm{C} 16$ and $\mathrm{C} 18$ fatty acids in cultures grown under both the conditions, which are considered suitable for biodiesel production.
\end{abstract}

Keywords: chlorella ellipsoidea, nitrogen replete, growth, lipid, linoleic acid
Volume 3 Issue I - 2017

\author{
Budhauliya R,' Purkayastha J,2 \\ 'Defence Research Laboratory, India \\ ${ }^{2}$ Defence Research and Development Organization, India
}

Correspondence: Jubilee Purkayastha, Institute of Nuclear Medicine and Allied Sciences, Delhi- I 10054, India, Tel +9 I8527558410,Email purkayasthaj@gmail.com

Received: October 31, 2016 | Published: May 09, 2017
Abbreviations: ACCase, acetyl-CoA carboxylase; qRT-PCR, quantitative real time PCR; FAME, fatty acid methyl ester; NIST, national institute of standards and technology; q-RT PCR, quantitative real time PCR; BBM, bolds basal medium; BC, biotin carboxylase; CT, carboxyl transferase; TAGs, triacylglycerides

\section{Introduction}

Microalgae based third generation biofuels are considered to be a reasonably viable alternative energy resource. This is because the biofuel derived from algae are found to be devoid of the major bottlenecks associated with first and second generation biofuels. This is because, some algae accumulates energy dense neutral lipid molecules in the form of triacylglycerides, which can be extracted and converted to fatty acid methyl esters (FAME), or biodiesel. Hence, in the present global scenario where increased use of renewable energy is highly encouraged, microalgae as a biodiesel feedstock is drawing immense attention. ${ }^{2}$ Among the microalgae explored, genus Chlorella has received much attention so far as Biodiesel source is concerned. ${ }^{3-5}$ In the genus Chlorella, it has been reported that Chlorella ellipsoidea have the potential to produce more biodiesel due to presence of high lipid content. ${ }^{6-7}$ It is a fact that high growth rate is very essential to increase yield per unit culture area and high lipid content is needed for FAME yield and to lessen the cost. ${ }^{8}$ Thus, proper balance of growth and lipid content is required for achieving cost effective means of lipid yield from microalgae.

Under stress, several species of microalgae can increase the rate of lipid biosynthesis to produce intracellular total lipids ${ }^{8}$ and triacylglycerides (TAGs) are the dominant form of lipids produced in microalgae. The accumulation of TAGs in microalgae has been replicated and understood from the knowledge of lipid metabolism from higher plants and bacteria. ${ }^{9}$ Recently, the role of lipases on cell membrane restructuring for lipid biosynthesis has also been revealed. ${ }^{10}$ The main gene responsible for the fatty acid biosynthesis and lipid production is Acetyl-coenzyme A carboxylase (ACCase) (ACC, E.C. 6.4.1.2). Acetyl-CoA carboxylase (ACC), catalyzes the irreversible carboxylation of acetyl-CoA to produce malonyl-CoA ${ }^{11}$ through biotin carboxylase (BC) and carboxyl transferase (CT). The most important function of ACC is to provide the malonyl-CoA substrate for the biosynthesis of fatty acids. ${ }^{12}$ Increased expression levels of ACCase in Chlorella sorokiniana, lead to the increased lipid content 
in stationary phase of mixotrophic growth. ${ }^{13}$ In the genus Chlorella it was also found that the same metabolic pathways in two species often response differently to the same outside environmental condition. ${ }^{14}$

The up-regulation of fatty acid and TAG biosynthetic pathways in response to nitrogen stress conditions was shown by proteomic analysis of the microalgae Chlorella vulgaris where a de novo assembled transcriptome was used as a search model..$^{15}$ In Chlorella pyrenoidosa, nitrogen starvation was shown as the effective approach to enhance lipid for biofuel production. ${ }^{16}$ Through metabolic flux analysis in Chlorella protothecoides, it was revealed that the carbon flux targeting into lipid synthesis was via acetyl-CoA. ${ }^{17}$ In NorthEast part of India, Chlorella ellipsoidea is a commonly occurring microalgae which can be considered as a potential one in terms of biodiesel, but it is yet to be realized. At the same time there is no study regarding Nitrogen stress affecting oil yield in C. ellipsoidea. Keeping these in mind, a study focussing on effect of Nitrogen stress on growth, lipid yield, fatty acid profile and expression of ACCase gene under Nitrogen repletion and depletion conditions were studied. We tried to see how under N-stress C. ellipsoidea grows, accumulate lipid and whether or not respond to little stress.

\section{Materials and methods}

\section{Isolation and identification of microalgae}

This study was carried out at the Defence Research Laboratory, Tezpur, Assam, India. Water samples as an isolating source of microalgae were collected from Padum Pukhuri, Tezpur in NorthEast India. The microalgae were subjected to purification by Serial dilution followed by plating. Algal samples were observed with a Zeiss Microscope at different stages of life cycle, either on cells in exponential phase or on cells in late stationary phase. Microalgae were identified as described by Carmelo, ${ }^{18}$ Kessler and Huss. ${ }^{19} \mathrm{~A}$ commonly occurring single cell microalgae isolate was identified as Chlorella ellipsoidea.

\section{Algal culture}

Stock cultures of $C$. ellipsoidea were maintained routinely on liquid medium (BBM) by regular sub-culturing at 3 weeks intervals. Cultures were maintained at $25 \pm 1{ }^{\circ} \mathrm{C}$ temperature with $1.2 \pm 0.2$ flux light intensity under 16:8 light dark cycles. Growth of C. ellipsoidea was monitored daily and was checked under microscope to confirm its purity. The individual colonies were isolated and inoculated in to liquid BBM (Bolds Basal Medium) and maintained (Table 1).

\section{Media neutralization and sterilization}

Bolds Basal Media (BBM) was prepared according to its composition as shown in Table 1. This media is prepared in two conditions Nitrogen repletion i.e. $\left(\mathrm{N}^{+}\right)$and Nitrogen stress or depletion $\left(\mathrm{N}^{-}\right)$(with $50 \% \mathrm{NaNO}_{3}$ ) for algal growth with $\mathrm{NaNO}_{3}$ as the nitrogen source. To neutralize the culture media, $0.1 \mathrm{~N} \mathrm{HCl}$ and $0.1 \mathrm{~N} \mathrm{NaOH}$ were used. After measuring the $\mathrm{pH}$ of the media, either acid or alkali were added by pipette and mixed thoroughly. When the media were acidic $\mathrm{NaOH}$ was added and when the media were alkaline $\mathrm{HCl}$ was added. This process was continued to make $\mathrm{pH}$ of media at 6.6 and to sterilize the culture media, the flasks containing the media were autoclaved at $121^{\circ} \mathrm{C}$ for $15 \mathrm{~min}$ with moist heat in an autoclave. After being autoclaved, media were kept, overnight to confirm if there were any contaminations.
Table I The composition of BBM media (For I litre). Macronutrient ' $\mathrm{NaNO}_{3}$ ' defined $\mathrm{N}^{+}$and $\mathrm{N}^{-}$conditions, where as all other components remained the same

\begin{tabular}{|c|c|c|c|}
\hline \multirow{2}{*}{ Macronutrients } & \multicolumn{2}{|c|}{$\begin{array}{l}\text { Stock solution }(\mathrm{G} / 100 \mathrm{ml} \text { d' } \\
\text { Water) }\end{array}$} & \multirow{2}{*}{$\begin{array}{l}\text { Aliquot } \\
\text { ( } 10 \mathrm{ml} / / \text { litre })\end{array}$} \\
\hline & $\mathbf{N}^{+}$ & $\mathbf{N}^{-}$ & \\
\hline $\mathrm{NaNO}_{3}$ & 2.5 & 1 & 10 \\
\hline $\mathrm{CaCl}_{2} \cdot 2 \mathrm{H}_{2} \mathrm{O}$ & 0.25 & 0.25 & 10 \\
\hline $\mathrm{MgSO}_{4} \cdot 7 \mathrm{H}_{2} \mathrm{O}$ & 0.75 & 0.75 & 10 \\
\hline $\mathrm{K}_{2} \mathrm{HPO}_{4}$ & 0.75 & 0.75 & 10 \\
\hline $\mathrm{KH}_{2} \mathrm{PO}_{4}$ & 1.75 & 1.75 & 10 \\
\hline $\mathrm{Nacl}$ & 0.25 & 0.25 & 10 \\
\hline
\end{tabular}

Alkaline EDTA solution

Chemicals Stock solution
(G/100ml d'Water)

Aliquot

EDTA

5

$\mathrm{KOH}$

3.1

Iml

\section{Acidified Iron solution}

Chemicals

Stock solution (G/100ml d'Water) Aliquot

$\mathrm{FeSO}_{4}$ 0.498

$\mathrm{H}_{2} \mathrm{SO}_{4}$

For dissolving of $\mathrm{H}_{2} \mathrm{SO}_{4}+\mathrm{H}_{2} \mathrm{O}$

Boron solution

Chemicals

Stock solution (G/100ml d'Water)

Aliquot

$\mathrm{H}_{3} \mathrm{BO}_{3}$

Iml

Trace metal solution

Chemicals

Stock solution (G/100ml d'Water)

Aliquot

$\mathrm{ZnSO}_{4} \cdot 7 \mathrm{H}_{2} \mathrm{O} \quad 0.882$

$\mathrm{Mncl}_{2} \cdot 4 \mathrm{H}_{2} \mathrm{O} \quad 0.114$

$\mathrm{MoO}_{3} \quad 0.071$

Iml
$\mathrm{CuSO}_{4} \cdot 5 \mathrm{H}_{2} \mathrm{O} \quad 0.157$

$\mathrm{Co}\left(\mathrm{No}_{3}\right)_{2} \cdot 6 \mathrm{H}_{2} \mathrm{O} \quad 0.049$ 


\section{Inoculation and culture conditions}

A 3 week old BBM media culture of C. ellipsoidea was used as inoculum at $10 \%$ for the Nitrogen repletion condition and also for Nitrogen stress condition. Cultures were grown in BBM media in culture room for 3 weeks for both $\mathrm{N}^{+}$and $\mathrm{N}^{-}$conditions. All the cultures were incubated at $25 \pm 1^{\circ} \mathrm{C}$ temperature with $1.2 \pm 0.2$ flux light intensity under 16:8 light dark cycles.

\section{Estimation and calculation of cell density and optical density}

Cell density was estimated using an improved Neubauer haemocytometer according to formula modified from Clesceri et al. ${ }^{20}$ The cell $\mathrm{mL}^{-1}$ were calculated by the following formula:

$$
\text { Cells per } m l=\frac{\text { Cell no. per } 16 \text { big squares }}{10^{-4}} x \text { dilution factor }
$$

Optical densities of the samples were determined at $680 \mathrm{~nm}$, by using UV spectrophotometer.

\section{Harvesting by vacuum filtration}

The harvesting process was completed by the vacuum filtration where GFC paper was used as filter (Supplementary Figure 1). The collected biomass on the GFC filter paper was then either used immediately for total RNA isolation or was freeze dried for lipid isolation and fatty acid analysis.

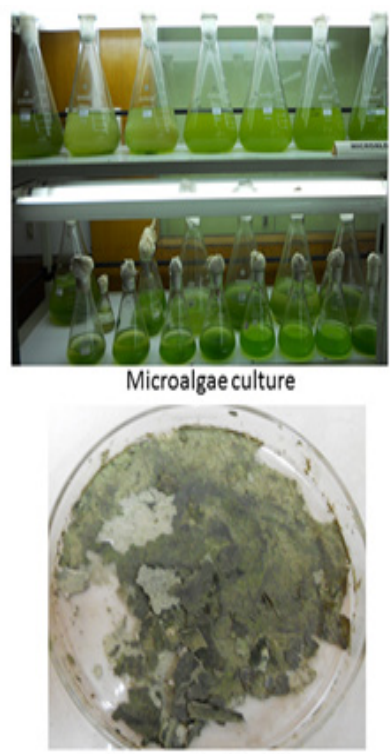

Dry biomass C. ellipsoide

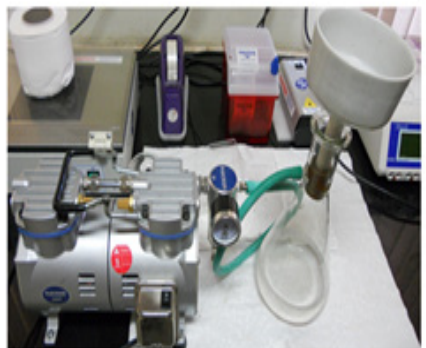

Vaccum pump for harvesting of Microalgae

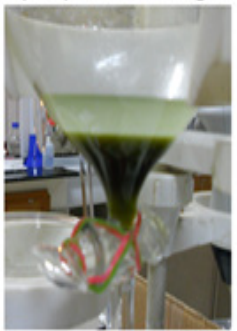

Lipid extraction from C. ellipsoidea by Bligh and Dyers Method
Supplementary Figure I Culture and harvesting of microalgae Chlorella ellipsoidea.

\section{Analytical methods}

\section{Biomass estimation}

The cultures were harvested after fixed time intervals and the cell wee washed with distilled water after centrifugation at 5000rpm for 10 minutes. Then the pellet was freeze dried. The dry weight of algal biomass was determined gravimetrically and growth was expressed in terms of dry weight $\left(\mathrm{gL}^{-1}\right)$.

\section{Lipid extraction}

Dried algal biomass was homogenized in a mortar pestle with liquid nitrogen for 15 minutes followed by homogenization in chloroform: methanol (1:2) and lipid was extracted following the method of Bligh and Dyer. ${ }^{21}$ The quantity of residue was measured gravimetrically and expressed as weight percentage.

\section{Fatty acid analysis}

The fatty acid profile of these lipid samples were obtained by analysing the fatty acid methyl esters. These were prepared by using a mass fraction of $2 \%$ sulphuric acid in methanol and were extracted into ethyl acetate and washed free of acid and dried over anhydrous sodium sulphate. The dried esters were further concentrated using a rotary evaporator and finally analyzed using GC. This was carried out using an Agilent 6850 series gas chromatography equipped with FID detector. A DB-225capillary column $(30 \mathrm{mx} 0.25 \mathrm{~mm}$ i.d) was used with the injector and detector temperature maintained at $230^{\circ} \mathrm{C}$ and $250^{\circ} \mathrm{C}$ respectively with a split ratio of 50:1. The carrier gas was nitrogen at a flow rate of $1.5 \mathrm{ml} \mathrm{min}^{-1}$. The column temperature was initially maintained at $160^{\circ} \mathrm{C}$ for $2 \mathrm{~min}$, increased to $180^{\circ} \mathrm{C}$, then further increased to $230^{\circ} \mathrm{C}$ at $4^{\circ} \mathrm{Cmin}^{-1}$ and finally maintained for $10 \mathrm{~min}$ at $230^{\circ} \mathrm{C}$. The FAMEs were identified by comparing their fragmentation pattern and retention index with NIST library.

\section{RNA extraction}

Cells for the $\mathrm{N}^{+}$and $\mathrm{N}^{-}$conditions were harvested by vacuum filtration. Dried algal biomass was homogenized in a mortar pestle with liquid nitrogen for 15 minutes. The total RNA was extracted and purified separately from each of the nitrogen replete and nitrogen depletion condition cultures using the RNeasy plant mini kit (Qiagen USA). Extracted RNA was electrophoresed on 1\% denaturing agarose gel at $40 \mathrm{~V}$.

\section{cDNA synthesis}

cDNA was prepared by using QuantiTect Reverse Transcription Kit (Quigen, CA, USA). Template RNA, Quantiscript RT buffer, genomic DNA wipeout buffer, quantiscript reverse transcriptase, RT primer mix and RNase free water were thawed on ice at room temperature. As per the kit, genomic DNA elimination reaction was prepared on ice (Supplementary Table 1). The purified RNA sample was briefly incubated in gDNA Wipeout Buffer at $42^{\circ} \mathrm{C}$ for 2 minutes to effectively remove contaminating genomic DNA. The RNA sample is then used directly in reverse transcription. As per the kit, the reverse-transcription master mix was prepared on ice (Supplementary Table 2). Reverse transcription was done using a master mix prepared from Quantiscript Reverse Transcriptase, Quantiscript RT Buffer and RT Primer Mix. The entire reaction was completed at $42^{\circ} \mathrm{C}$ and is then inactivated at $95^{\circ} \mathrm{C}$ for 15 minute to inactivate the quantiscript reverse transcriptase.

\section{Primer design and PCR amplification of ACCase}

Degenerate Primers were designed based on the highly conserved nucleotide sequences reported for the ACCase gene for the amplification of partial cDNA from C. ellipsoidea (Table 2). The primers were screened for ACCase gene amplification. In order to demonstrate suitability of cDNA for PCR amplification a $25 \mu \mathrm{l}$ reaction mixture was set up under the following conditions: $0.5 \mu \mathrm{l}$ template cDNA (50ng), $0.5 \mu 1$ Taq DNA polymerase enzyme (2.5U), 
$0.5 \mu 1 \mathrm{dNTP}(200 \mu \mathrm{M}), 2.5 \mu 1$ Taq DNA polymerase buffer (1X), $2 \mu 1$ $\mathrm{MgCl}_{2}(2 \mathrm{mM})$ and $0.25 \mu \mathrm{l}$ each oligonucleotide ACF4 and ACR4 primers $(2.0 \mu \mathrm{M}), 18.75 \mu \mathrm{ldd} \mathrm{H}_{2} \mathrm{O}$. The amplification reaction was carried out in a thermal cycler (G-Storm) with initial denaturation at $94^{\circ} \mathrm{C}$ for $1 \mathrm{~min}$ and followed by 38 cycles of denaturation at $94^{\circ} \mathrm{C}$ for $1 \mathrm{~min}$, annealing at $53^{\circ} \mathrm{C}$ for $1 \mathrm{~min}$ and extension at $72^{\circ} \mathrm{C}$ for $1 \mathrm{~min}$ and final extension for $7 \mathrm{~min}$ at $72^{\circ} \mathrm{C}$.

Table 2 The designed primers and their sequence used in this study

\begin{tabular}{ll}
\hline Primer name & Primer sequence \\
\hline ACFI & CTGGTCGTCGGGTGATTGAA \\
ACRI & GCCCACGTTCACCATAAGGA \\
ACF2 & AATACGTGGCGTCCCTTTGA \\
ACR2 & CCTGTTCGTTCTTGTGCGTC \\
ACF3 & TAGTTTGTGCTTCTGGCGGA \\
ACR3 & GTTCAATCACCCGACGACCA \\
ACF4 & CGAACAGGTCTGCAAGATGC \\
ACR4 & TGTTCAATCACCCGACGACC \\
ACF5 & ATACGTGGCGTCCCTTTGAT \\
ACR5 & GCATCTTGCAGACCTGTTCG \\
accdF0 & TTAGARTTTMRAGATCAAAAAGC \\
accdR0 & CCRGCAAAMCCAATTAAAGCTTT \\
accdFI & AAGATGCTCAAGAAAGAACCGG \\
accdrI & TACACCGCCTGTTGTCGGAG \\
\hline
\end{tabular}

\section{Semi-quantitative estimation of PCR products}

The PCR products $\left(8 \mu \mathrm{l}\right.$ amount) of both cDNA $\left(\mathrm{N}^{+}\right.$and $\mathrm{N}^{-}$ conditions) were electrophoresed on $1 \%$ agarose gel for $50 \mathrm{~min}$ at $40 \mathrm{~V}$ and visualized by ethidium bromide staining and photographed under ultraviolet light in gel documentation system. Based on the band intensity of both PCR products, the semi-quantitative estimation of ACCase gene expression was performed.

\section{Quantitative real- time PCR analysis of ACCase gene}

The quantitative analysis of ACCase gene expression was done by Quantitative Real-Time PCR (qRT-PCR) (Light Cycler 488, Roche). The designed primer (ACF3 and ACR3) were used for Quantitative Real-Time PCR experiments. Reaction was set as: RNase free water $(3.5 \mu 1)$, Reverse primer i.e. ACR4 $(2.5 \mu \mathrm{l})$, Forward primer i.e. ACF4 $(2.5 \mu 1)$, Template, cDNA $(4 \mu 1)$ and SYBR green PCR Master mix $(1 \mathrm{x})$ $(12.5 \mu 1)$. Total $25 \mu \mathrm{l}$ amount were prepared with three replications of Nitrogen stress $\left(\mathrm{N}^{-}\right)$condition as Target and three with Nitrogen repletion $\left(\mathrm{N}^{+}\right)$as control with ACF4/ACR4 primer pairs. And a negative control without template for both nitrogen conditions were also done, i.e. total 7 reactions were prepared for real-time PCR set up. ITS gene was used as internal control in the Real Time PCR experiment (Supplementary Table 3). The PCR program consisted of a preliminary step of $5 \mathrm{~min}$ at $95^{\circ} \mathrm{C}$ followed by two step cycling of 40 cycles at $95^{\circ} \mathrm{C}$ for $10 \mathrm{sec}$ and at $60^{\circ} \mathrm{C}$ for $30 \mathrm{sec}$. Gene expression levels were analysed on the basis of individual $\mathrm{Cp}$ (Crossing Point) value of target gene and control gene, with the help of a graph with florescence. The mean fold change in expression of the ACCase gene of $C$. ellipsoidea in $\mathrm{N}^{-}$and $\mathrm{N}^{+}$was normalized relative to the house keeping gene and calculated by the formula $2^{-\Delta \Delta C T}$, where $\Delta \Delta C T=\left(C_{T}\right.$ Target $\left.-\mathrm{C}_{\text {T ITS }}\right) \mathrm{N}^{-}-\left(\mathrm{C}_{\text {T Target }}-\mathrm{C}_{\text {T ITS }}\right) \mathrm{N}^{+}$.

\section{Results}

\section{Growth study}

C. ellipsodea growth study was performed by two methods-Cell density and Optical density (at $680 \mathrm{~nm}$ ), under nitrogen repletion and nitrogen depletion condition.

\section{Growth study in nitrogen repletion condition}

Results (Figure $1 \& 2$ ), showed that the initial optical density (at $680 \mathrm{~nm}$ ) of C. ellipsoidea in $\mathrm{N}^{+}$condition was 0.0263 in BBM media, which goes to the highest mean value of 0.1929 on 21 day. Similarly, the initial cell density was $26.58 \times 10^{4}$, which goes to increased mean value of $6820 \times 10^{5}$ on 21 day.

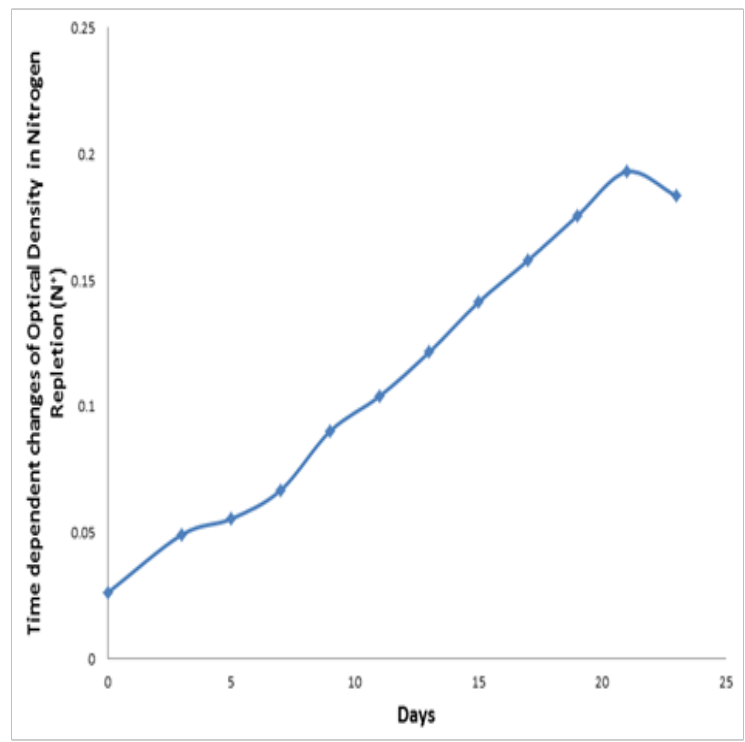

Figure I Time dependent changes of optical density of $C$. ellipsoidea cultures in nitrogen repletion $\left(\mathrm{N}^{+}\right)$condition in BBM media.

\section{Growth study in nitrogen depletion condition}

Similarly, in case of $\mathrm{N}^{-}$condition (Figure $3 \& 4$ ) the initial optical density of C. ellipsoidea was 0.003833 , which increased up to 0.1184 on 19 day after inoculation and the initial cell density increased from $9.66 \times 10^{4}$ to $1733 \times 10^{5}$ on 19 day. So, the growth rate under nitrogen repletion condition is higher as compared to nitrogen depletion condition. It is an interesting observation that cells continue to grow post nitrogen deprivation till 19 days. With the decrease in cell growth in $\mathrm{N}$ media, the appearance of the culture changed, turning from dark green to yellow.

\section{Lipid productivity}

Lipid productivity under $\mathbf{N}^{+}$condition: The lipid productivity of $C$. ellipsoidea under nitrogen repletion $\left(\mathrm{N}^{+}\right)$condition was $12 \%$ on dry weight basis.

Lipid productivity under $\mathbf{N}^{-}$condition: In the same way, the lipid productivity under Nitrogen stress condition was $17 \%$ after 23 day 
of harvesting. Our analysis showed, that the lipid contents under depletion culture condition was much higher than those under repletion culture conditions, reaching nearly $17 \%$ of the dry weight.

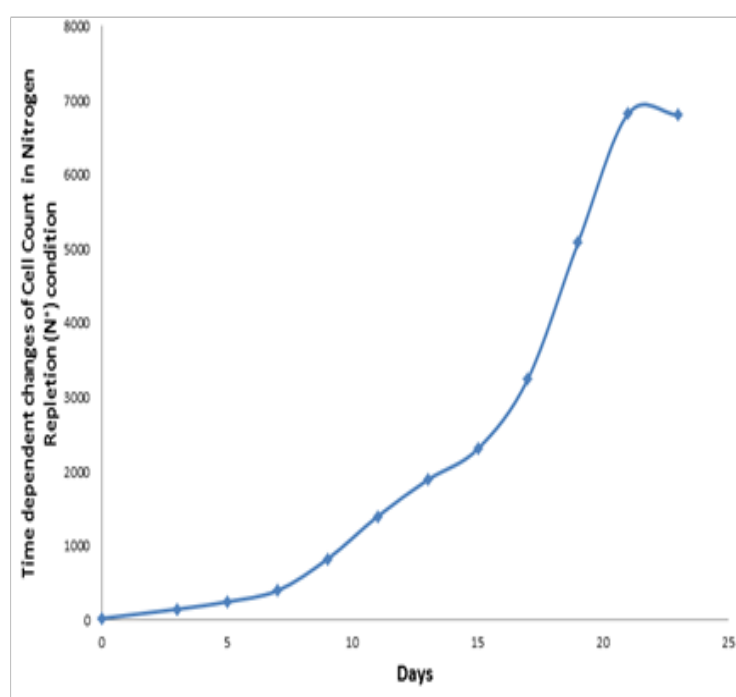

Figure 2 Time dependent changes of cell count of $C$. ellipsoidea cultures in nitrogen repletion $\left(\mathrm{N}^{+}\right)$condition in BBM media.

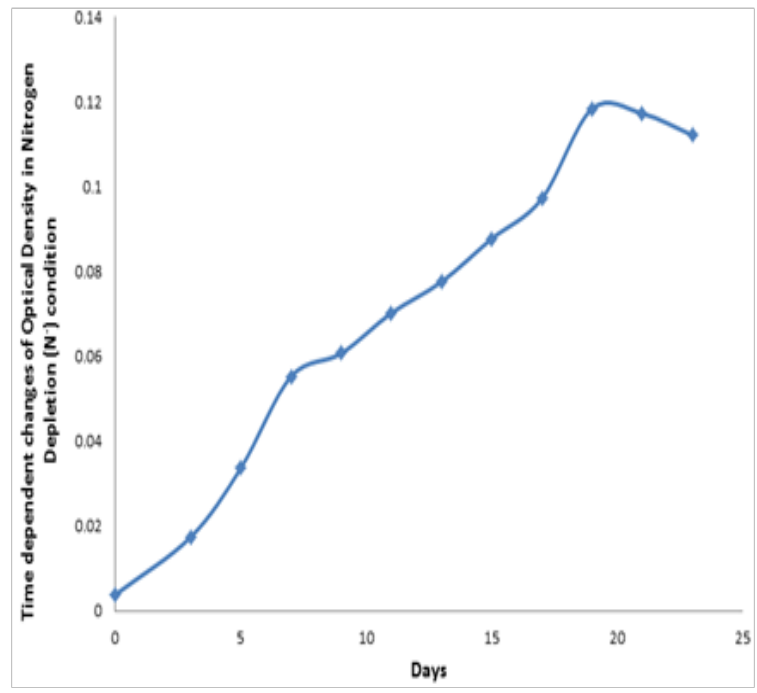

Figure 3 Time dependent changes of optical density of $C$. ellipsoidea cultures in nitrogen depletion ( $\mathrm{N}^{-}$) condition in BBM media.

\section{Fatty acid analysis}

C16 and C18 fatty acids comprised major components in both the cases (Table 3). The main components were palmitic acid (C16:0), oleic acid (C18:1), stearic acid (C18:0) and linoleic acid (C18:2) in cultures grown under nitrogen replete condition in BBM media. In cultures grown under nitrogen deplete condition in BBM media, the main components were palmitic acid (C16:0), oleic acid (C18:1) and linoleic acid (C18:2), however, stearic acid (C18:0) showed a sharp decline in case of cultures grown under nitrogen deplete condition as compared to nitrogen replete condition in BBM media. However, $\alpha$-linolenic acid (18:3) showed a sharp increase from $20.3 \%$ to $32.6 \%$ from Nitrogen repletion to Nitrogen depletion cultures.

\section{RNA extraction}

The extracted RNA (from both $\mathrm{N}^{+}$and $\mathrm{N}^{-}$Conditions), of $C$. ellipsodea from RNeasy plant mini kit (Quigen, CA, USA) were run on the $1 \%$ Agarose gel electrophoresis at $60 \mathrm{~V}$ for 50 minutes. Then in both cases the two clear bands of RNA were seen in the gel (Supplementary Figure 2) which showed the purification of RNA.

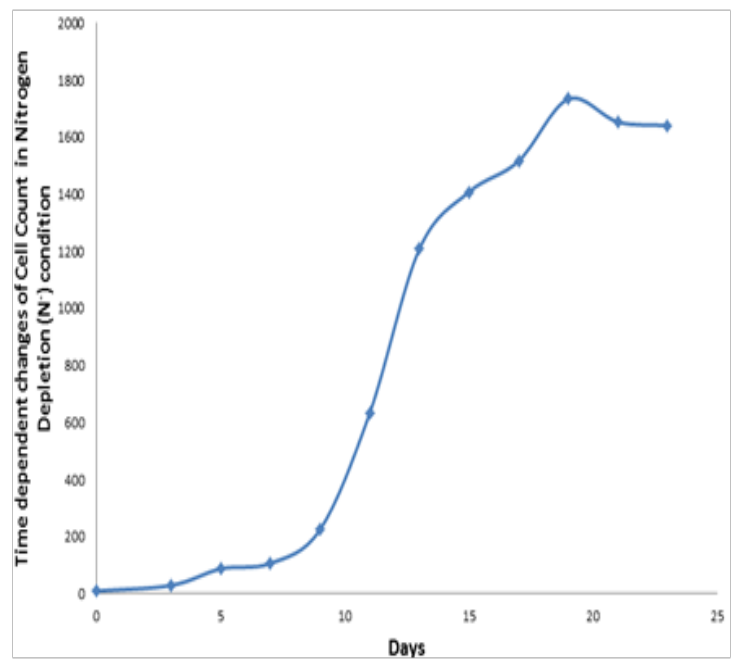

Figure 4 Time dependent changes of cell count of $C$. ellipsoidea cultures in nitrogen depletion $(\mathrm{N})$ condition in BBM media.

Table 3 Fatty acid profile of chlorella ellipsoidea grown in bold basal media under nitrogen repletion $\left(\mathrm{N}^{+}\right)$and nitrogen depletion $(\mathrm{N})$ conditions

\begin{tabular}{lll}
\hline \multirow{2}{*}{ Fatty acids } & \multicolumn{2}{l}{ C. Ellipsoidea } \\
\cline { 2 - 3 } & BBM $\left(\mathbf{N}^{+}\right)$ & BBM (N) \\
\hline $12: 00$ & 2.1 & 1.1 \\
$14: 00$ & 1.9 & 1 \\
$16: 00$ & 39.5 & 30.6 \\
$16: 01$ & 4.8 & 4.8 \\
$17: 00$ & 4.6 & 16.6 \\
18:00 & 9 & 3.5 \\
18:01 & 9.4 & 3.2 \\
18:02 & 5.9 & 5.2 \\
18:03 & 20.3 & 32.6 \\
$20: 00$ & 0.9 & 0.4 \\
$24: 00: 00$ & 1 & 0.5 \\
\hline
\end{tabular}

\section{cDNA amplification and semi-quantitative analysis of PCR products}

Out of the PCR primers screened for ACCase amplification, ACCase specific primer pair ACF4/ACR4 showed distinct band and thus this primer pair was used for comparative study of ACCase gene expression in subsequent study. The product of PCR amplification using ACCase specific primer pairs ACF4/ACR4 for cDNAs sourced from Nitrogen repletion $\left(\mathrm{N}^{+}\right)$and nitrogen depletion $\left(\mathrm{N}^{-}\right)$conditions were electrophoresed on $1 \%$ Agarose gel at $40 \mathrm{~V}$ for 1 hour. The results showed a clear difference in band intensity with a very intense band for $\mathrm{N}^{-}$condition as compared to $\mathrm{N}^{+}$conditions. So, the higher band intensity of the $\mathrm{N}^{-}$condition ACCase gene showed the more expression or up-regulation, while lower intensity of Nitrogen repletion $\left(\mathrm{N}^{+}\right)$ showed the less or down regulation of ACCase gene, which means the 
ACCase gene was more expressed in Nitrogen depletion condition as compare to Nitrogen repletion (Supplementary Figure 3).

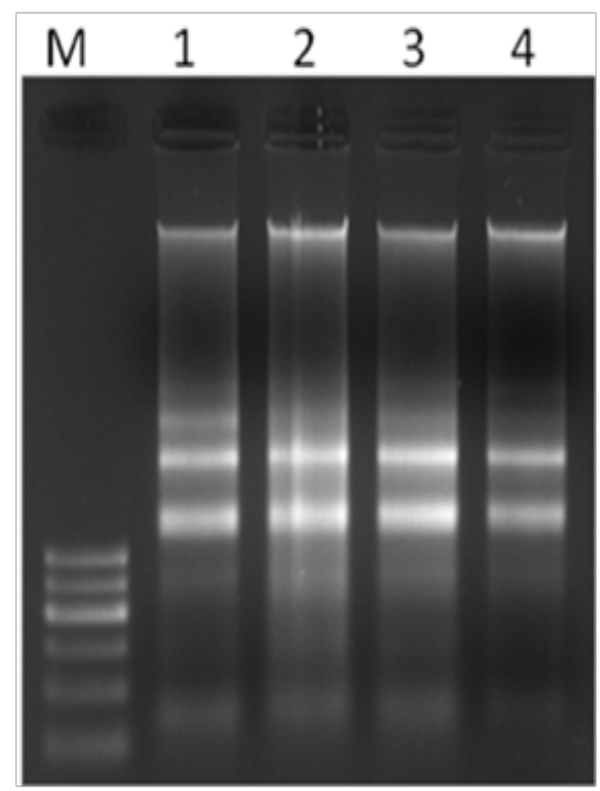

Supplementary Figure 2 Electrophoretic separation of total RNA of $C$. elipsoidea under $\mathrm{N}$-repletion $(\mathrm{I}, 2)$ and $\mathrm{N}$-depletion $(3,4)$. M: I00bp ladder.

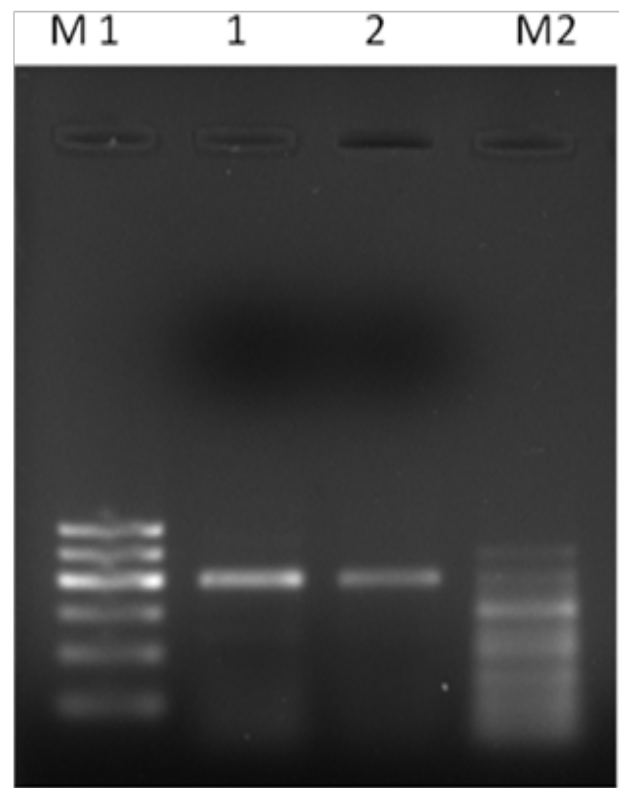

Supplementary Figure 3 Semi-quantitative analysis of ACCase gene expression optimized using Primer pair:ACF4/ACR4. MI: I00bp ladder DNA; I: ACCase from $\mathrm{N}$ - sourced culture of $C$. ellipsoidea; 2 : $A C$ Case from $\mathrm{N}^{+}$ sourced culture of $C$. ellipsoidea; $M 2$ : 50bp ladder DNA

\section{Quantification of ACCase gene expression by quanti- tative real-time PCR}

Quantitative real time PCR (qRT-PCR) analysis of ACCase gene from Nitrogen repletion $\left(\mathrm{N}^{+}\right)$and Nitrogen depletion $\left(\mathrm{N}^{-}\right)$conditions showed 0.6322 fold up-regulation of ACCase gene in Nitrogen depletion $\left(\mathrm{N}^{-}\right)$cultures of $C$. ellipsoidea cultures as compared to Nitrogen repletion $\left(\mathrm{N}^{+}\right)$cultures. Melting curve analysis using fluorescence against temperature indicates that only a single product has been amplified in the qPCR reaction (Figure 5).

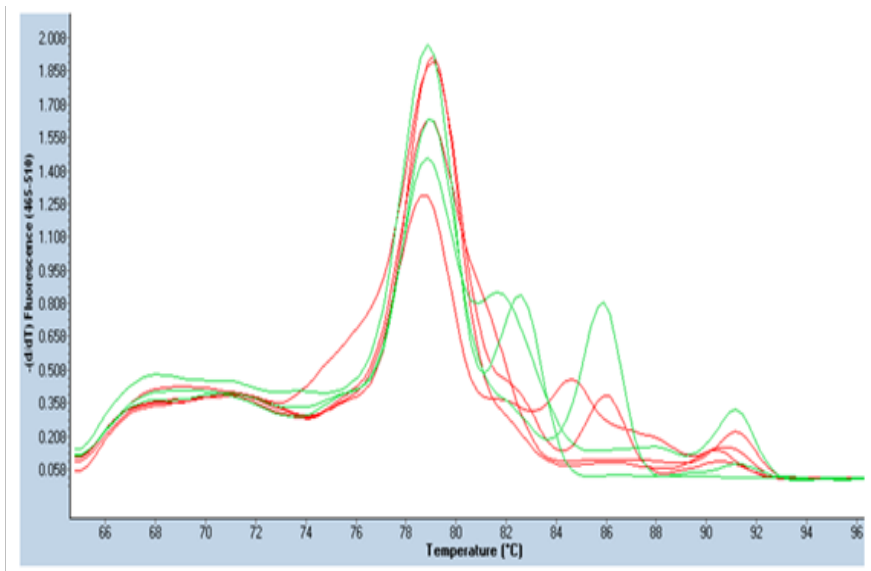

Figure $5 \mathrm{~A}$ melting curve plot of fluorescence. The fluorescence level shows a sharp decrease around the amplicon melting temperature of $82^{\circ} \mathrm{C}$.

\section{Discussion}

Selection of suitable algal strains is a critical step in realizing the full potential of commercial scale microalgal cultivation for biodiesel production. An ideal production strains should high growth and lipid yield and should be robust in cultivation. ${ }^{8}$ Not only organic carbon, nitrogen, vitamins, salts and other nutrients are vital for microalgal growth. ${ }^{22}$ Under nitrogen depletion $\left(\mathrm{N}^{-}\right)$condition, microalgae can be induced to accumulate substantial quantities of lipids thus contributing to a higher oil yield. ${ }^{23}$ In this experiment the high growth rate of $C$. ellipsoidea under nitrogen stress as well as in nitrogen repletion was observed on 21 day, so the best time for harvesting or collecting the biomass with high growth rate and more biomass was after 3 week of inoculation, because at that time the exponential phase of cycle occurs. After 21 days of cultivation period, 10L of culture medium was harvested by vacuum filtration pump, to obtain biomass from the microalgal culture. Harvesting of microalgae in a cost effective way is a major concern of algal based biodiesel. Methods used and proposed for harvesting algae are very costly due to the large quantity of chemicals flocculants required if proper harvesting is desired. Also, waste water treatment, harvesting efficiency and cost is a critical problem in algal control. ${ }^{23}$ So, the harvesting of microalgal culture and collection of biomass both are the main challenge regarding the production of biodiesel from microalgae. ${ }^{24}$

The lipid present in dried biomass was extracted by using chloroform: methanol (2:1) by Bligh and Dyer. ${ }^{18}$ After the extraction it was shown that the high lipid content $\%$ was present in Nitrogen depletion condition (17\%) as compare to Nitrogen repletion condition $(12 \%)$. High lipid productivity is a key characteristic of a suitable algal species for biodiesel production. ${ }^{8}$ The abundant growth of cells may deplete the nitrogen source in the culture. Earlier also, the lack of nitrogen has been shown to improve the lipid content. Perhaps, a lack of nitrogen or some other nutrient may be the main reason for shifting from growth to high lipid content in the stationary phase of the mixotrophic Chlorella cultures. ${ }^{25}$

The fatty acid analysis showed, $\mathrm{C} 16$ and $\mathrm{C} 18$ fatty acids as to comprise major components in both the cases of nitrogen repletion as well as depletion. The main components were palmitic acid (C16:0), oleic acid (C18:1), stearic acid (C18:0) and linoleic acid (C18:2) in cultures grown under nitrogen replete condition in BBM media. In cultures grown under nitrogen deplete condition in BBM media, the main components were palmitic acid (C16:0), oleic acid (C18:1) and 
linoleic acid (C18:2), however, stearic acid (C18:0) showed a sharp decline in case of cultures grown under nitrogen deplete condition as compared to nitrogen replete condition in BBM media, However, $\alpha$-linolenic acid (18:3) showed a sharp increase from $20.3 \%$ to $32.6 \%$ from Nitrogen repletion to Nitrogen depletion cultures. High principal costs due to low lipid productivity of fatty acids synthesizing microalgae are one of the major logjam, hampering the commercial production of microalgal lipid derived biodiesel. It is now an obvious fact that to obtain high lipid content external stress or lipid induction techniques need to be applied. But the type and duration of the stress need to be optimized from time to time. Under ideal growth conditions, many microalgae produce saturated and unsaturated fatty acids naturally, which might have high nutritional value, but may be less suitable for biodiesel. However, under stress conditions, the synthesis of neutral lipids in the form of TAG can be induced which are suitable for biodiesel production. The types of TAGs produced are species, strain and culture specific and are finally controlled by the genetic make-up of individual organisms. Also, synthesis and accumulation of TAGs along with substantial modifications in lipid and fatty acid composition can occur in microalgae when allowed to grow under stress conditions. The stress may be induced by chemical or physical either acting independently or jointly. There are a wide range of studies carried out on lipid enhancement techniques in microalgae including nutrients stress, especially nitrogen. ${ }^{2,4}$

Nitrogen is the single most important nutrient affecting lipid metabolism in micro algae. A common tendency towards lipids accumulation, particularly TAG, in response to nitrogen deficiency has been observed in numerous species/strains of various microalgae. Study on nitrogen stress reactions of several green microalgae, diatoms and cyanobacteria showed a significant rise in lipid production. ${ }^{9}$ Results showed that TAG biosynthetic machinery is up-regulated significantly. In this study the up-regulation can again likely be attributed to the last stage of harvesting of nitrogen deplete cells. Guarnieri et al. ${ }^{15}$ showed that under nutrient replete conditions, representative $C$. vulgaris cells were found to accumulate a few small, discrete green fluorescent lipid droplets. However, under nitrogen deprivation, most C. vulgaris cells accumulated large lipid droplets that appear to encompass the bulk of the intercellular space. The product of PCR amplification using ACCase specific primer pairs ACF4/ACR4 for cDNAs sourced from Nitrogen repletion $\left(\mathrm{N}^{+}\right)$and nitrogen depletion $\left(\mathrm{N}^{-}\right)$conditions were electrophoresed on $1 \%$ Agarose gel at $40 \mathrm{~V}$ for 1hour. The results showed a clear difference in band intensity with a very intense band for $\mathrm{N}^{-}$condition as compared to $\mathrm{N}^{+}$conditions So, the higher band intensity of the $\mathrm{N}$ - condition ACCase gene showed the more expression or up-regulation, while lower intensity of Nitrogen repletion $\left(\mathrm{N}^{+}\right)$showed the less or down regulation of ACCase gene, which means the ACCase gene more expressed in Nitrogen depletion condition as compare to Nitrogen repletion. Quantitative real time PCR (qRT-PCR) analysis of ACCase gene from Nitrogen repletion $\left(\mathrm{N}^{+}\right)$and nitrogen depletion $\left(\mathrm{N}^{-}\right)$conditions showed 0.6322 fold up regulation of ACCase gene in Nitrogen depletion $\left(\mathrm{N}^{-}\right)$cultures of $C$. ellipsoidea cultures as compared to Nitrogen repletion $\left(\mathrm{N}^{+}\right)$cultures.

Wan et al. ${ }^{13}$ reported that in C. sorokiniana the increased lipid contents in stationary phases of mixotrophic growth were related to increased expression levels of $a c c D$ gene. Cho et al. ${ }^{14}$ reported that the expression levels of $a c c D$ gene began to increase during the exponential phases under heterotrophic cultivations, but raised expression of this gene did not lead to increased lipid contents in the same manner as in the stationary phases. In this experiment, the reason behind upregulation of ACCase under stress leading to lipid accumulation may me that the many of the other fatty acid biosynthetic pathway components are up-regulated under nitrogen depletion condition. The decreased nitrogen concentration might have led to an elevated ratio of carbon to nitrogen, then improved expression levels of ACCase gene. This may be of value in designing strategies for improving lipid synthesis for biodiesel production in C. ellipsoidea. Furthermore, whether the activity of ACCase in this species is also regulated via other manners needs further research.

\section{Conclusion}

The C. ellipsoidea is a major and potential microalgae for the biodiesel production, which is commonly growing in freshwater of North East India. Regarding the experimental findings, we observed that the growth rate, lipid content, fatty acid profile and Acetyl-CoA carboxylase (ACCase) gene expression showing variations under nitrogen repletion and nitrogen depletion conditions. The growth rate which was observed by two methods optical density and cell density, so the growth rate was more in nitrogen repletion condition as compared to nitrogen depletion, However, the lipid percentage was more in Nitrogen depletion condition than in repletion condition. Fatty acid methyl esters (FAME) analysis showed that the main components were $\mathrm{C} 16$ and $\mathrm{C} 18$ fatty acids in cultures grown under nitrogen replete condition, which are considered suitable for biodiesel production. The ACCase gene expression which were analysed by two ways as semi-quantitatively and by quantitative Real-Time PCR(q-RT PCR). In both the ways it was observed that more gene expression or upregulation was found in the nitrogen depletion condition as compared to nitrogen repletion condition. The findings especially on growth, lipid, fatty acid profile and ACCase gene expression changes in terms of nitrogen repletion and depletion conditions opens up new area of research for large scale biodiesel production from C. ellipsoidea.

\section{Acknowledgements}

We thank Director, DRL, Tezpur, India for providing the facilities and support required for this study and Director General-Life Sciences, DRDO HQ for permission to publish this work. This work was funded by the Defence Research and Development Organization, India.

\section{Conflict of interest}

The author declares no conflict of interest.

\section{References}

1. Brennan L, Owende P. Biofuels from microalgae- A review of technologies for production processing and extractions of biofuels and co-products. Renewable And Sustainable Energy Reviews. 2010;14(2):557577

2. Adams $\mathrm{C}$, Godfrey $\mathrm{V}$, Wahlen $\mathrm{B}$, et al. Understanding precision nitrogen stress to optimize the growth and lipid content tradeoff in oleaginous green microalgae. Bioresour Technol. 2013;131:188-194.

3. Feng P, Deng Z, Hu Z, et al. Lipid accumulation and growth of Clorellazofingensis in flat plate photobioreactors outdoor. Bioresource Technology. 2011;102(22):10577-10584.

4. Mujtaba G, Choi W, Lee CG, et al. Lipid production by Chlorella vulgaris after a shift from nutrient rich to nitrogen starvation conditions. Bioresour Technol. 2012;123:279-283.

5. Wang B, Lan CQ, Horsman M. Closed photo-bioreactors for production of microalgal biomasses. Biotechnol Adv. 2012;30(4):904-912.

6. Ayhan D, Demirbas MF. Importance of algae oil as a source of biodiesel Energy Conversion and Management. 2012;52(1):163-170. 
7. Singh J, Gu S. Commercialization potential of microalgae for biofuels production. Renewable and Sustainable Energy Reviews. 2010;14(9):2596-2610.

8. Griffiths MJ, Harrison STL. Lipid productivity as a key characteristic for choosing algal species for biodiesel production. J Appl Phycol. 2009;21(5):493-507.

9. $\mathrm{Hu} \mathrm{Q}$, Sommerfeld M, Jarvis E, et al. Microalgal triacylglycerols as feed stocks for biofuel production: perspectives and advances. Plant J. 2008;54(4):621-639.

10. Miller R, Wu G, Deshpande RR, et al. Changes in transcript abundance in Clamydomonasreinhadtii following nitrogen deprivation predict diversion of metabolism. Plant Physiol. 2010;154(4):1737-1752.

11. Sasaki Y, Nagano Y. Plant acetyl-CoA carboxylase:structure, biosynthesis, regulation and gene manipulation for plant breeding. Biosci Biotechnol Biochem. 2004;68(6):1175-1184.

12. Tong L. Acetyl-coenzyme A carboxylase: crucial metabolic enzyme and attractive target for drug discovery. Cell Mol Life Sci. 2005;62(16):17841803

13. Wan M, Liu P, Xia J, et al. The effect of mixotrophy on microalgal growth, lipid content, and expression levels of three pathway genes in Chlorella sorokiniana. Appl Microbiol Biotechnol. 2011;91(3):835-844.

14. Cho S, Lee D, Luong TT, et al. Effects of carbon and nitrogen sources on fatty acid contents and composition in the green microalgae, Chlorella sp. 227. J Microbiol Biotechnol. 2011;21(10):1073-1080.

15. Guarnieri MT, Nag A, Smolinski SL, et al. Examination of triacylglycerol biosynthetic pathways via de novo transcriptomic and proteomic analyses in an unsequenced microalgae. PLoS One. 2011;6(10):e25851.
16. Nigam S, Rai MP, Sharma R. Effect of nitrogen on growth and lipid content of chlorella pyrenoidosa. American Journal of Biochemistry and Biotechnology. 2011;7(3):124-129.

17. Miao X, Wu Q. Biodiesel production from heterotrophic microalgal oil. Bioresour Technol. 2006;97(6):841-846.

18. Carmelo RT. Identifying Marine Phytoplankton. Florida, USA: Academic Press; 1997. p. 844-858.

19. Kessler E, Huss VAR. Comparative physiology and biochemistry and taxonomic assignment of the Chlorella (Chlorophyceae) strains of the culture collection of the University of Texas at Austin. Journal of Phycology. 1992;28(4):550-553

20. Clesceri LS, Greenberg AE, Trussell RR. Standard methods for the examination of water and wastewater. American Water Works Association and Water Pollution Control Federation. New York, USA: American public health association; 1989. p. 92-1110.

21. Bligh EG, Dyer WJ. A rapid method for total lipid extraction and purification. Can J Biochem Physiol. 1959;37(8):911-917.

22. Mata TM, Martins AA, Caetano NS. Microalgae for biodiesel production and other applications. Renewable and Sustainable Energy Reviews. 2010;14(1):217-232.

23. Sheehan J, Dunahay T, Benemann J, et al. A Look Back at the US Department of Energy's Aquatic Species Program-Biodiesel from Algae Close-Out Report. USA: National Renewable Energy Lab; 1998.

24. Jing L, Xiaoqian M. The analysis on energy and environmental impacts of microalgae-based fuel methanol in China. Energy Policy. 2009;37:1479-1488.

25. Hsieh $\mathrm{CH}, \mathrm{Wu}$ WT. Cultivation of microalgae for oil production with a cultivation strategy of urea limitation. Bioresource Technology. 2009;100(17):3921-3926 